\title{
Dietary intake of n-3 long-chain polyunsaturated fatty acids and risk of myocardial infarction in coronary artery disease patients with or without diabetes mellitus: a prospective cohort study
}

Elin Strand ${ }^{1 *}$, Eva R Pedersen ${ }^{1}$, Gard FT Svingen ${ }^{1}$, Hall Schartum-Hansen², Eirik W Rebnord ${ }^{2}$, Bodil Bjørndal ${ }^{1}$, Reinhard Seifert ${ }^{2}$, Pavol Bohov ${ }^{1}$, Klaus Meyer ${ }^{3}$, J Kalervo Hiltunen ${ }^{4,5}$, Jan E Nordrehaug ${ }^{1,2}$, Dennis WT Nilsen ${ }^{1,6}$, Rolf K Berge ${ }^{1,2,5}$ and Ottar Nygård ${ }^{1,2,5}$

\begin{abstract}
Background: A beneficial effect of a high n-3 long-chain polyunsaturated fatty acid (LCPUFA) intake has been observed in heart failure patients, who are frequently insulin resistant. We investigated the potential influence of impaired glucose metabolism on the relation between dietary intake of $n-3$ LCPUFAs and risk of acute myocardial infarction (AMI) in patients with coronary artery disease.

Methods: This prospective cohort study was based on the Western Norway B-Vitamin Intervention Trial and included 2,378 patients with coronary artery disease with available baseline glycosylated hemoglobin (HbA1c) and dietary data. Patients were sub-grouped as having no diabetes (HbA1c $<5.7 \%$ ), pre-diabetes $(\mathrm{HbA} 1 \mathrm{c} \geq 5.7 \%$ ), or diabetes (previous diabetes, fasting baseline serum glucose $\geq 7.0$, or non-fasting glucose $\geq 11.1 \mathrm{mmol} / \mathrm{L}$ ). AMl risk was evaluated by Cox regression (age and sex adjusted), comparing the upper versus lower tertile of daily dietary n-3 LCPUFA intake.
\end{abstract}

Results: The participants (80\% males) had a mean age of 62 and follow-up of 4.8 years. A high n-3 LCPUFA intake was associated with reduced risk of AMI (hazard ratio $0.38,95 \% \mathrm{Cl} 0.18,0.80$ ) in diabetes patients (median HbA1c $=7.2 \%$ ), whereas no association was observed in pre-diabetes patients. In patients without diabetes a high intake tended to be associated with an increased risk (hazard ratio $1.45,95 \% \mathrm{Cl} 0.84,2.53$ ), which was significant for fatal AMI (hazard ratio $4.79,95 \% \mathrm{Cl} 1.05,21.90$ ) and associated with lower HbA1c (mean \pm standard deviation $4.55 \pm 0.68$ versus $4.92 \pm 0.60, P=0.02$ ). No such differences in $\mathrm{HbA} 1 \mathrm{c}$ were observed in those with pre-diabetes or diabetes.

Conclusions: $A$ high intake of $n-3$ LCPUFAs was associated with a reduced risk of AMI, independent of HbA1c, in diabetic patients, but with an increased risk of fatal AMI and lower HbA1c among patients without impaired glucose metabolism. Further studies should investigate whether patients with diabetes may benefit from having a high intake of n-3 LCPUFAs and whether patients with normal glucose tolerance should be careful with a very high intake of these fatty acids.

Trial registration: This trial is registered at clinicaltrials.gov as NCT00354081.

Keywords: Coronary artery disease, Diabetes, Dietary n-3 fatty acids, Myocardial infarction

\footnotetext{
* Correspondence: Elin.Strand@med.uib.no

'Department of Clinical Science, University of Bergen, 5021 Bergen, Norway

Full list of author information is available at the end of the article
} 


\section{Background}

Dietary intakes of fish and omega-3 (n-3) long-chain polyunsaturated fatty acids (LCPUFAs), mainly eicosapentaenoic acid (EPA) and docosahexaenoic acid (DHA), have been associated with a reduced risk of cardiovascular disease and mortality [1,2]. A diet rich in these fatty acids (FAs) is recommended in secondary prevention of coronary heart disease [3]. However, two recent meta-analyses of randomized controlled trials, investigating n-3 LCPUFA intake through diet or supplements, failed to demonstrate an overall preventive effect on cardiovascular events $[4,5]$. Furthermore, a recent large randomized controlled trial among patients at high cardiovascular risk showed no reduction in heart disease or cardiac death after treatment with $1 \mathrm{~g} /$ day of n-3 LCPUFA [6].

Randomized trials with n-3 LCPUFA intervention have shown reduced mortality [7] and improved left ventricular systolic function and functional capacity $[8,9]$ among patients with heart failure, who are frequently insulin resistant [10]. In general, patients with diabetes mellitus are at increased risk of cardiovascular disease complications, including acute myocardial infarction (AMI) and mortality, as compared to patients without diabetes [11]. There is, however, conflicting evidence regarding associations between dietary n-3 LCPUFAs and cardiovascular events among patients with diabetes [12-17]. A recently published large randomized controlled trial of 12,536 patients with dysglycemia (ORIGIN), failed to demonstrate a benefit of daily n-3 LCPUFA supplementation [18]. Participants had a baseline dietary n-3 LCPUFA intake of approximately $200 \mathrm{mg} /$ day and median glycosylated hemoglobin (HbA1c) of $6.4 \%$. The intervention group received $1 \mathrm{~g} /$ day of $n-3$ LCPUFAs, while the placebo group received $1 \mathrm{~g} /$ day of olive oil. Notably, mortality rate in ORIGIN was higher than could be expected (2.57\%) [18] compared to other trials investigating glucose lowering therapy in patients with diabetes. The ACCORD trial (baseline median HbA1c 8.1\%) had a mortality rate of $1.41 \%$ in the intensive treatment group and demonstrated that aggressive glucose lowering in patients with diabetes, targeting HbA1c $<6.0 \%$, may be associated with increased mortality [19]. Based on this, the overall intensive glucose lowering in ORIGIN may have influenced the negative results regarding $n-3$ LCPUFA supplements.

Our previous investigation on the current population of Norwegian patients with established coronary artery disease (CAD) showed no overall reduction in risk of coronary events with increasing intakes of n-3 LCPUFAs [20]. No sub-group analyses were, however, conducted. Based on the reported beneficial effects in patients with heart failure [7-9], the current investigation evaluated the association of n-3 LCPUFA intake with risk of AMI in patients with no diabetes, pre-diabetes, or established diabetes, respectively, in the patient cohort previously studied. We hypothesized that participants with diabetes mellitus would benefit from a high intake of n-3 LCPUFAs.

\section{Methods}

\section{Study population}

The current investigation was a prospective cohort study based on participants from the Western Norway B-Vitamin Intervention Trial (WENBIT) [21]. In short, this was a clinical trial conducted between 1999 and 2006 at Haukeland University Hospital and Stavanger University Hospital in Western Norway, including 3,090 patients undergoing coronary angiography for suspected CAD, and who were randomized to treatment with B vitamins. Overall, there was no short- or long-term benefits on cardiovascular outcomes or all-cause mortality associated with the study treatment [21].

Figure 1 gives an overview of patient selection for the final inclusion in the present analysis based on 2,484 patients who completed a semi-quantitative food-frequency

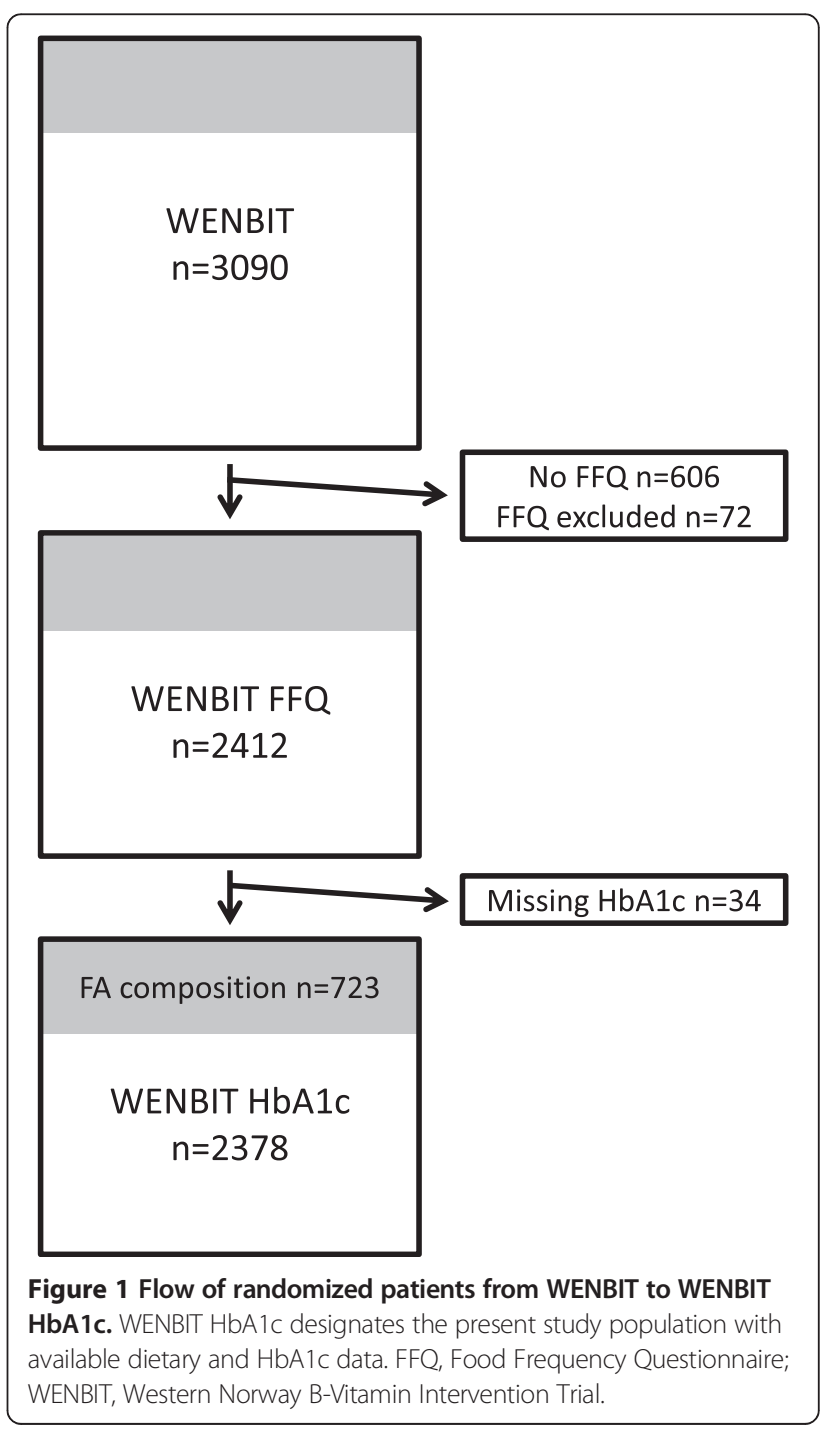


questionnaire (FFQ) at trial enrolment between 2000 and 2004. Nineteen questionnaires were excluded because they contained more than one blank page. Extreme outliers of dietary intake were excluded based on the assumption that these did not represent their usual daily intakes. These outliers were identified by participants having very low $(<3,000 \mathrm{~kJ}$ for women and $<3,300 \mathrm{~kJ}$ for men) or very high $(>15,000 \mathrm{~kJ}$ for women and $>17,500 \mathrm{~kJ}$ for men) estimated daily energy intakes $(n=53)$, leaving 2,412 patients with valid dietary data. Further, 34 individuals were excluded because of missing HbA1c data, leaving 2,378 patients for the final analyses. Serum FA composition was determined in a sub-set of 723 patients.

All participants gave written informed consent. The study protocol was in accordance with the principles of the Declaration of Helsinki, and it was approved by the Regional Committee for Medical Research Ethics, the Norwegian Medicines Agency, and the Data Inspectorate. WENBIT is registered at clinicaltrials.gov as NCT00354081.

\section{Dietary assessment}

An FFQ developed at the Department of Nutrition, University of Oslo, validated against plasma phospholipid n-3 LCPUFA concentrations [22], was given to patients at enrolment and returned by mail to the study center or collected at the first follow-up appointment one month later. A more detailed description of the structure and organization of the 169 food item FFQ and inclusion/ exclusion criteria for this sub-study have been given previously [20]. Briefly, the usual daily intake of $n-3$ LCPUFAs during the last year was estimated based on FFQ reported food items and supplements containing EPA, docosapentaenoic acid (DPA, 22:5n-3), and DHA. Calculations were made by using a database and a software system developed at the Department of Nutrition, University of Oslo (Kostberegningssystem, version 3.2; University of Oslo, Norway) [23].

\section{Assessment of other covariates}

Demographic, clinical, and routine laboratory data were obtained by study personnel at the respective two study centers as previously described [21]. Serum samples were collected before angiography and stored at $-80^{\circ} \mathrm{C}$ until analysis, while standard blood laboratory parameters were analyzed from fresh samples according to routine protocols at their central hospital laboratories. Reagent kits of type Tina-quant ${ }^{\circ}$ on apolipoprotein A-I (Apo A-I, ver.2), apolipoprotein B (Apo B, ver.2), and C-reactive protein (latex, high sensitive assay) were obtained from Roche Diagnostics (Mannheim, Germany), and serum measurements were done on the Hitachi 917 system (Roche Diagnostics). HbA1c was determined by matrix-assisted laser desorption/ionization time-of-flight mass spectrometry [24] and plasma cotinine by liquid chromatography/tandem mass spectrometry at BEVITAL AS (http://www.bevital.no, Bergen, Norway). Serum FA methyl esters were obtained and analyzed by gas-liquid chromatography as previously described [25]. Smokers included self-reported current smokers, those reported having quit within the last four weeks, and patients with plasma cotinine $\geq 85 \mathrm{nmol} / \mathrm{L}$. Left ventricular ejection fraction was determined by ventriculography or echocardiography, and values $<50 \%$ were considered equaling impaired systolic function. Estimated glomerular filtration rate was calculated applying the equation by the Chronic Kidney Disease Epidemiology Collaboration [26]. Extent of CAD was graded as clinically non-significant stenosis (luminal narrowing $<50 \%$ ), or as having single-, double-, or triple vessel disease.

\section{Endpoints and follow-up}

The endpoints in this study were fatal and non-fatal AMI, classified according to the diagnostic criteria of the revised definition of myocardial infarction from 2000 [27]. Procedure-related non-fatal AMI occurring $\leq 24$ hours after coronary angiography, percutaneous coronary intervention (PCI), or coronary artery bypass graft surgery (CABG) were excluded. Information on AMIs was collected from the Western Norway Cardiovascular Registry and from the Norwegian Cause of Death Registry. Endpoints were recorded during in-trial and post-trial follow-up until 31 December 2006, and all events were adjudicated by members of the WENBIT endpoints committee.

\section{Statistical analyses}

Categorization of the participants was based on established diagnostic criteria for no-, pre-, and overt diabetes mellitus [28]. Participants were thus classified as non-diabetic (no prior history of diabetes and HbAlc <5.7\%), prediabetic (no prior history of diabetes and HbA1c $25.7 \%$ ), and diabetic (previously diagnosed diabetes or fasting baseline serum glucose $\geq 7.0$ or a non-fasting glucose $\geq 11.1 \mathrm{mmol} / \mathrm{L}$ ). Means ( \pm standard deviation (SD)) or medians $\left(25^{\text {th }}, 75^{\text {th }}\right.$ percentile) and proportions of various clinical and biochemical parameters were calculated for selected baseline characteristics and dietary variables within each category. Simple comparisons of continuous variables within or between sub-groups were made by the t-test. Spearman's rank correlation was used to assess associations between various continuous parameters. The Kolmogorov-Smirnov test was used to examine the continuous FA variables for normal distribution. Variables that were not normally distributed were log-transformed. Estimated marginal means (95\% confidence interval (CI)) of FA profile were calculated for each sub-group by one-way analysis of covariance, with adjustments made for age, sex, and statin dose. Post-hoc comparisons were made by using the Tukey honestly significant difference for specifying between-group 
differences in FA composition as assessed by analysis of covariance.

Participants within each group were ranked into tertiles according to combined daily n-3 LCPUFA (EPA, DPA, and DHA) intake as percentage of total energy (\%TE) intake. Survival curves were created for follow-up until the $95^{\text {th }}$ percentile of follow-up time (corresponding to 6.8 years) using the Kaplan-Meier method. Hazard ratios (HRs) and 95\% CI were estimated by Cox proportional hazards modeling. Tests for trend were performed using estimated daily n-3 LCPUFA tertiles as a continuous variable in otherwise identical models. The basic model included age and sex. Additional covariates in the multivariate model were selected on the basis of clinical relevance and included the following: fasting (dichotomous), current smoking (dichotomous) [29], extent of CAD (non-significant; single-, double-, or triple-vessel disease), left ventricular ejection fraction (continuous), serum triglycerides (continuous), baseline acute coronary syndrome (dichotomous), baseline PCI (dichotomous), baseline CABG (dichotomous), and randomization to treatment with folic acid or vitamin B6 study medication (dichotomous). Interactions between intake of n-3 LCPUFAs and diabetes were tested by adding interaction product terms in the model. Additional adjustments for the following covariates did not appreciably alter the results and were not included in the final model: body mass index (continuous); current use of statins, $\beta$-blockers, angiotensin-converting enzyme inhibitors, angiotensin receptor blockers, metformin, sulfonamides, and insulin (dichotomous for all); history of hypertension (dichotomous); and apolipoprotein A-I and B, HbA1c, or $\mathrm{C}$-reactive protein (continuous for all).

Statistics were performed using IBM SPSS Statistics for Windows, version 19 (SPSS, Chicago, IL, USA) and R version 2.15.2 (R Development Core Team, Vienna, Austria). Two-sided $P$-values $<0.05$ were considered statistically significant.

\section{Results}

\section{Baseline characteristics and dietary intakes}

At baseline, the mean age of the participants was 61.6 years and $80.4 \%$ were men. Further, $84.6 \%$ had stable angina pectoris. A total of $46.6 \%$ were treated for hypertension and $31.1 \%$ were current smokers. A previous myocardial infarction was reported in $41.3 \%$, PCI in $21.5 \%$, and CABG in $14.0 \%$ of the patients. On baseline coronary angiography, $11.2 \%$ were diagnosed with non-significant CAD, and $32.0 \%$ had three-vessel disease. At discharge from hospital, 90.1\% of the participants were treated with aspirin, $22.7 \%$ with calcium channel blockers, and 9.3\% with loop diuretics. A total of 1,577 patients $(66.3 \%)$ underwent myocardial revascularization with either PCI or CABG. There were 1,012 patients $(42.6 \%)$ classified as non-diabetic, 1,049 (44.1\%) classified as pre-diabetic, and 317 (13.3\%) classified as diabetic, of whom $16(0.7 \%)$ had type 1 and 301 (12.7\%) type 2 diabetes.

Characteristics of participants in the sub-groups are presented in Table 1. Patients with diabetes (median HbA1c $7.2 \%)$ were older $(P=0.001)$, had a higher body mass index $(P<0.001)$, and more frequently had hypertension $(P<0.001)$. As expected, they had overall higher triglycerides $(P<0.001)$ and lower apolipoprotein A-I $(P<0.001)$ compared to nonand pre-diabetic participants. Patients with diabetes also had a higher intake of total fat $(P=0.02)$ and monounsaturated fat $(P=0.002)$. There were no differences between the groups regarding intakes of saturated and trans fat.

\section{Dietary intake of n-3 LCPUFAs and fish}

Mean $( \pm$ SD) daily dietary intakes of $n-3$ LCPUFAs among all 2,378 participants were $0.43 \pm 0.24,1.08 \pm 0.37$, and $2.38 \pm 1.15 \mathrm{~g} /$ day for tertiles 1 to 3 of $\mathrm{n}-3$ LCPUFA, respectively. Adjusted for energy intake, this corresponded to $0.18 \pm 0.08,0.45 \pm 0.09$, and $1.03 \pm 0.40 \% \mathrm{TE}$, respectively. Mean $( \pm$ SD) intakes of $n-3$ LCPUFAs (\%TE) were $0.56 \pm 0.44$ for non-diabetic, $0.54 \pm 0.40$ for pre-diabetic, and $0.60 \pm 0.46$ for diabetic patients. Intakes were higher among diabetic patients compared to pre-diabetic patients $(P=0.04)$. Tertiles of mean $( \pm \mathrm{SD})$ daily intakes according to the sub-groups were $0.17 \pm 0.08,0.44 \pm 0.09$, and $1.05 \pm 0.42 \% \mathrm{TE}$ for nondiabetic patients; $0.18 \pm 0.08,0.44 \pm 0.08$, and $0.98 \pm 0.38 \% \mathrm{TE}$ for pre-diabetic patients; and $0.19 \pm 0.08,0.48 \pm 0.11$, and $1.12 \pm 0.42 \% \mathrm{TE}$ for patients with diabetes. Total daily fish intake (mean \pm SD) in tertiles 1 to 3 was $47.7 \pm 19.0$, $98.0 \pm 13.7$, and $180.7 \pm 62.1 \mathrm{~g} /$ day, respectively.

\section{Serum fatty acid profile}

FA profile in serum from a sub-cohort of 723 patients was used to determine whether estimated dietary intake of FAs was reflected in serum. We observed a strong association between reported intake and serum total n-3 LCPUFAs (Spearman's rho $=0.515, P<0.001$ ). Table 2 shows main serum FA profile in percentage by weight ( $w \mathrm{t} \%)$ of total FAs in sub-groups of patients with no diabetes $(n=380)$, prediabetes $(n=259)$, and diabetes $(n=84)$. When adjusted for age, sex, and statin dose, serum total FAs (mg/L) were borderline significantly higher in the diabetic group as compared to those with pre-diabetes (Tukey honestly significant difference, $P=0.05)$. Furthermore, serum saturated FAs were higher (wt\%) while n-6 PUFAs were lower in patients with diabetes compared to those with no diabetes and pre-diabetes (Tukey honestly significant difference, $P<0.05$ for all between-group comparisons). There was no difference in total or individual n-3 LCPUFAs between the three sub-groups.

\section{Follow-up and events}

Mean $( \pm \mathrm{SD})$ length of follow-up was $4.8 \pm 1.4$ years. A total of 208 participants $(8.7 \%)$ experienced a fatal or non-fatal 
Table 1 Baseline characteristics of participants $(n=2,378)$

\begin{tabular}{|c|c|c|c|c|}
\hline & $\begin{array}{c}\text { Non-diabetes } \\
\text { HbA1c }<5.7 \% \\
n=1,012\end{array}$ & $\begin{array}{c}\text { Pre-diabetes } \\
\text { HbA1c } \geq 5.7 \% \\
n=1,049\end{array}$ & $\mathrm{n}=317$ & $P^{\mathbf{b}}$ \\
\hline Age (y) & $61.0 \pm 9.9^{c}$ & $61.8 \pm 9.5$ & $63.1 \pm 9.5$ & 0.001 \\
\hline Male sex (n (\%)) & $800(79.1)$ & $855(81.5)$ & $256(80.8)$ & 0.28 \\
\hline Body mass index $\left(\mathrm{kg} / \mathrm{m}^{2}\right)$ & $26.5 \pm 3.4$ & $26.7 \pm 3.6$ & $28.4 \pm 4.3$ & $<0.001$ \\
\hline \multicolumn{5}{|l|}{ Coronary history (n (\%)) } \\
\hline Myocardial infarction & $410(40.5)$ & $432(41.2)$ & $139(43.8)$ & 0.34 \\
\hline Percutaneous coronary intervention & $209(20.7)$ & $229(21.8)$ & $74(23.3)$ & 0.29 \\
\hline Coronary artery bypass graft surgery & $135(13.3)$ & $150(14.3)$ & $47(14.8)$ & 0.44 \\
\hline \multicolumn{5}{|l|}{ Coronary risk factors (n (\%)) } \\
\hline Hypertension $^{d}$ & $430(42.5)$ & $461(43.9)$ & $217(68.5)$ & $<0.001$ \\
\hline Current smoker $^{\mathrm{e}}$ & $313(30.9)$ & $339(32.3)$ & $88(27.8)$ & 0.57 \\
\hline \multicolumn{5}{|l|}{ Serum lipids } \\
\hline Triglycerides (mmol/L) & $1.73 \pm 1.28$ & $1.76 \pm 1.00$ & $2.17 \pm 1.27$ & $<0.001$ \\
\hline Apolipoprotein A-I (g/L) & $1.28 \pm 0.25$ & $1.24 \pm 0.25$ & $1.22 \pm 0.26$ & $<0.001$ \\
\hline Apolipoprotein B (g/L) & $0.90 \pm 0.25$ & $0.86 \pm 0.23$ & $0.88 \pm 0.22$ & 0.004 \\
\hline \multicolumn{5}{|l|}{ Glucose status } \\
\hline Glucose (mmol/L) & $5.6 \pm 1.1$ & $5.8 \pm 1.1$ & $9.8 \pm 3.4$ & $<0.001$ \\
\hline HbA1c (\%) & $4.9 \pm 0.6$ & $6.5 \pm 0.8$ & $7.5 \pm 1.8$ & $<0.001$ \\
\hline \multicolumn{5}{|l|}{ Inflammation markers and renal function } \\
\hline C-reactive protein $(\mathrm{mg} / \mathrm{L})^{f}$ & $1.76(0.85,3.68)$ & $1.85(0.89,4.23)$ & $2.07(1.00,4.40)$ & 0.45 \\
\hline Estimated glomerular filtration rate (mL/min) & $90.0 \pm 15.3$ & $90.7 \pm 14.4$ & $88.8 \pm 17.5$ & 0.61 \\
\hline \multicolumn{5}{|c|}{ LVEF and severity of coronary artery disease at baseline angiography (n (\%)) } \\
\hline LVEF $<50 \%$ & $89(8.8)$ & $118(11.2)$ & $44(13.9)$ & 0.006 \\
\hline Three-vessel disease & $316(31.2)$ & $330(31.5)$ & $115(36.3)$ & 0.19 \\
\hline \multicolumn{5}{|l|}{ Medication at discharge from hospital (n (\%)) } \\
\hline Statins & $889(87.8)$ & $948(90.4)$ & $280(88.3)$ & 0.35 \\
\hline$\beta$-blockers & $800(79.1)$ & $817(77.9)$ & $236(74.4)$ & 0.11 \\
\hline ACE inhibitors/ARBs & $263(26.0)$ & $330(31.5)$ & $159(50.2)$ & $<0.001$ \\
\hline Metformin & $0(0)$ & $0(0)$ & $98(30.9)$ & 0.98 \\
\hline Sulfonamides & $0(0)$ & $0(0)$ & $79(24.9)$ & 0.98 \\
\hline Insulin & $0(0)$ & $0(0)$ & $77(24.3)$ & 0.98 \\
\hline Other anti-diabetic drugs & $0(0)$ & $0(0)$ & $4(1.3)$ & 0.98 \\
\hline \multicolumn{5}{|l|}{ Estimated daily dietary intakes } \\
\hline Energy (kJ) & $8,790 \pm 2,560$ & $8,900 \pm 2,740$ & $8,300 \pm 2,680$ & 0.06 \\
\hline Total fat (\%TE) & $31.2 \pm 5.4$ & $31.4 \pm 5.4$ & $32.2 \pm 6.2$ & 0.02 \\
\hline Saturated and trans fat (\%TE) & $11.6 \pm 2.6$ & $11.6 \pm 2.6$ & $11.7 \pm 2.8$ & 0.35 \\
\hline Monounsaturated fat (\%TE) & $10.1 \pm 1.9$ & $10.1 \pm 1.9$ & $10.5 \pm 2.2$ & 0.002 \\
\hline Polyunsaturated fat (\%TE) & $7.0 \pm 1.9$ & $7.0 \pm 2.0$ & $7.3 \pm 2.3$ & 0.07 \\
\hline $\mathrm{n}-6$ PUFAs $(\mathrm{g})^{9}$ & $13.3 \pm 6.3$ & $13.6 \pm 6.7$ & $13.1 \pm 6.6$ & 0.96 \\
\hline $\mathrm{n}-3$ PUFAs $(\mathrm{g})^{\mathrm{h}}$ & $3.23 \pm 1.54$ & $3.25 \pm 1.61$ & $3.24 \pm 1.67$ & 0.89 \\
\hline $\mathrm{n}-3$ LCPUFAs $(\mathrm{g})^{\mathrm{i}}$ & $1.30 \pm 1.11$ & $1.28 \pm 1.05$ & $1.32 \pm 1.06$ & 0.96 \\
\hline n-3 LCPUFAs (\%TE) ${ }^{i}$ & $0.56 \pm 0.44$ & $0.54 \pm 0.40$ & $0.60 \pm 0.46$ & 0.45 \\
\hline
\end{tabular}


Table 1 Baseline characteristics of participants $(\mathbf{n}=\mathbf{2 , 3 7 8 )}$ (Continued)

\begin{tabular}{|c|c|c|c|c|}
\hline \multicolumn{5}{|c|}{ Use of dietary supplements (n (\%)) } \\
\hline Fish oil & $167(16.5)$ & $171(16.3)$ & $49(15.5)$ & 0.69 \\
\hline Cod liver oil & $272(26.9)$ & $294(28.0)$ & $80(25.2)$ & 0.83 \\
\hline Folic acid & $500(49.4)$ & 523 (49.9) & 161 (50.8) & 0.68 \\
\hline Vitamin B6 & $508(50.2)$ & $545(52.0)$ & $145(45.7)$ & 0.44 \\
\hline
\end{tabular}

AMI. The incidence of AMI was $7.6 \%$ for non-diabetic, $8.4 \%$ for pre-diabetic, and $13.6 \%$ for diabetic patients.

Intake of n-3 LCPUFAs and risk of acute myocardial infarction Figure 2 illustrates the crude event-free survival time from AMI among patients with or without diabetes in tertiles of n-3 LCPUFA intake. The age and sex- and multivariateadjusted HRs for AMI according to tertiles of n-3 LCPUFA consumption (\%TE) in sub-groups, as estimated by Cox proportional hazards modeling, are presented in Table 3. Compared to the lower tertile, the multivariate adjusted risk of experiencing an AMI was non-significantly increased by $55 \%$ among patients without diabetes, having intakes corresponding to the upper tertile $(P=0.13)$. There was no association between n-3 LCPUFA consumption and risk of AMI in patients with pre-diabetes, and restricting the analysis to patients with $\mathrm{HbA} 1 \mathrm{c} \geq 6.5 \%$ ( $\mathrm{n}=423$ ) provided similar results (data not shown). Among patients with diabetes, there was a $62 \%$ risk reduction of experiencing an AMI in the upper compared to the lower tertile of n-3 LCPUFA intakes in multivariate analysis $(P=0.02)$, and there was also a dose-response effect $(P$ for trend $=0.01)$. Adding all patients with $\mathrm{HbA} 1 \mathrm{c} \geq 6.5 \%$ to the diabetes group clearly attenuated the associations, providing a multivariate adjusted HR $(95 \% \mathrm{CI})$ of $0.71(0.40,1.26)$ in the upper versus lower tertile of n-3 LCPUFA intakes and no dose-response relationship. Estimates based on $\mathrm{mg} /$ day amounts of $\mathrm{n}-3$ LCPUFAs were very similar and did not introduce any material changes to the percentage of total energy findings (data not shown). There were no clear associations between total fish intake and AMI risk (Table 3).

Conventional criteria on diagnosing diabetes by blood glucose rely on two separate measurements [28]. Since 59 patients were included in the diabetes group based on baseline glucose from one single measurement, we did a separate sensitivity analysis among the 258 patients who were diagnosed with diabetes prior to baseline examination, and this did not change the results (data not shown). Because patients with diabetes tended to have an increased n-3 LCPUFA intake compared to the others, we repeated the analysis on the diabetes sub-group using tertiles based on the total population. This analysis provided similar results (data not shown). There was an interaction between diabetes and n-3 LCPUFA in a multivariate adjusted

Table 2 Serum fatty acid profile in percentage by weight (wt\%) measured in 723 participants

\begin{tabular}{|c|c|c|c|c|}
\hline & $\begin{array}{l}\text { Non-diabetes } \mathrm{HbA} 1 \mathrm{c}<5.7 \% \\
\qquad \mathrm{n}=380\end{array}$ & $\begin{array}{l}\text { Pre-diabetes } \mathrm{HbA} 1 \mathrm{c} \geq 5.7 \% \\
\qquad n=259\end{array}$ & $\begin{array}{c}\text { Diabetes }^{\mathrm{a}} \\
\mathrm{n}=84\end{array}$ & $P^{\mathbf{b}}$ \\
\hline Total FAs (mg/L) & $3,790(3,680 \text { to } 3,900)^{c}$ & $3,680(3,560$ to 3,810$)$ & $4,050(3,820$ to 4,300$)$ & 0.02 \\
\hline Saturated FAs & $33.2(32.9$ to 33.4$)$ & 33.2 (32.9 to 33.5$)$ & 34.0 (33.5 to 34.5$)$ & 0.01 \\
\hline Monounsaturated FAs & 22.9 (22.5 to 23.2$)$ & $23.2(22.7$ to 23.6$)$ & $24.0(23.2$ to 24.8$)$ & 0.03 \\
\hline n-6 PUFAs & $35.0(34.4$ to 35.5$)$ & 34.5 (33.9 to 35.2$)$ & 32.8 (31.8 to 33.9$)$ & 0.002 \\
\hline n-3 PUFAs & $7.2(7.0$ to 7.5$)$ & 7.4 (7.1 to 7.8$)$ & $7.2(6.6$ to 7.8$)$ & 0.61 \\
\hline a-Linolenic acid & 0.71 (0.69 to 0.73 ) & $0.73(0.70$ to 0.75$)$ & 0.72 (0.68 to 0.77 ) & 0.38 \\
\hline Eicosapentaenoic acid & 1.80 (1.68 to 1.92$)$ & 1.91 (1.76 to 2.07$)$ & $1.78(1.54$ to 2.05$)$ & 0.49 \\
\hline Docosapentaenoic acid (n-3) & 0.62 (0.60 to 0.63$)$ & $0.63(0.61$ to 0.65$)$ & 0.62 (0.58 to 0.65$)$ & 0.55 \\
\hline Docosahexaenoic acid & 3.69 (3.56 to 3.82 ) & 3.73 (3.58 to 3.90$)$ & 3.63 (3.37 to 3.91$)$ & 0.79 \\
\hline n-3 PUFA / n-6 PUFA ratio & 0.21 (0.20 to 0.22$)$ & $0.22(0.20$ to 0.23$)$ & $0.22(0.20$ to 0.24$)$ & 0.41 \\
\hline
\end{tabular}

${ }^{a}$ Diabetes was defined as clinically diagnosed, or as having a fasting glucose $\geq 7.0$ or a non-fasting glucose $\geq 11.1 \mathrm{mmol} / \mathrm{L}$. ${ }^{\mathrm{b}} \mathrm{Calculated}$ by using one-way analysis of

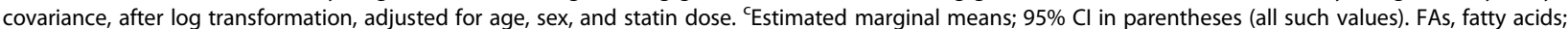
HbA1c, glycosylated hemoglobin; PUFAs, polyunsaturated fatty acids. 

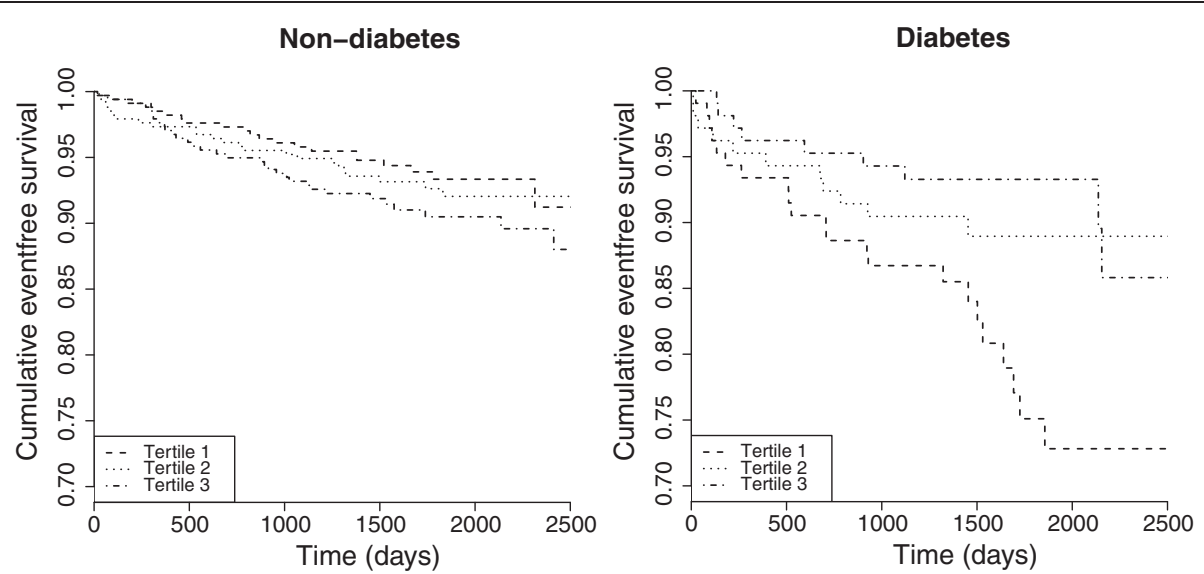

Figure 2 Kaplan-Meier plot illustrating survival in patients with or without diabetes mellitus. Survival plot showing time to an acute myocardial infarction in each tertile of n-3 LCPUFA intakes (designated as Tertile 1,2, and 3) in patients without diabetes (HbA1c $<5.7 \%$ ) (left panel) and with diabetes (right panel). Estimates were based on follow-up until the $95^{\text {th }}$ percentile (6.8 years).

interaction analysis $(P$ for interaction $=0.02)$. Adjusting for study treatment with B vitamins according to the WENBIT study design did not materially affect any of the results.

We also performed stratified analyses according to fataland non-fatal AMI as outcomes (Table 4). Among patients without diabetes, HR $(95 \% \mathrm{CI})$ for fatal AMI was 4.79 $(1.05,21.90)$ in the upper versus lower tertile of $n-3$ LCPUFA intake $(P$ for trend $=0.02)$. In patients with diabetes, HR $(95 \% \mathrm{CI})$ for fatal AMI was $0.22(0.06,0.81)$ in tertile 3 compared to tertile 1 ( $P$ for trend $=0.02$ ). For non-fatal AMI, there was no change in risk among patients without diabetes, but a non-significant trend towards a reduced risk with increasing intakes among patients with diabetes. Due to the low number of events in each sub-group, the multivariate model did not converge for separate fatal- and non-fatal AMIs. Thus, only ageand sex adjusted HRs were presented for these separate endpoints (Table 4).

Post hoc comparisons within the non-diabetic group revealed that $\mathrm{HbA1c}$ was lower in tertiles $2(P=0.008)$ and $3(P=0.01)$, compared to tertile 1 of $\mathrm{n}-3$ LCPUFA intakes (mean \pm SD $4.87 \pm 0.62$ and $4.87 \pm 0.65$ versus $4.99 \pm 0.54$ ).

Table 3 Risk of total acute myocardial infarction by dietary n-3 LCPUFA (as a percentage of total energy intake) and fish (grams) tertiles

\begin{tabular}{|c|c|c|c|c|c|c|}
\hline & \multicolumn{2}{|c|}{ Non-diabetes (HbA1c $<5.7 \%, n=1,012)$} & \multicolumn{2}{|c|}{ Pre-diabetes $(\mathrm{HbA} 1 \mathrm{c} \geq 5.7 \%, \mathrm{n}=1,049)$} & \multicolumn{2}{|l|}{ Diabetes $(n=317)^{a}$} \\
\hline & Age/sex adjusted & Multivariate $^{\mathbf{b}}$ & Age/sex adjusted & Multivariate $^{b}$ & Age/sex adjusted & Multivariate $^{\mathbf{b}}$ \\
\hline Number of events & \multicolumn{2}{|c|}{77} & \multicolumn{2}{|c|}{88} & \multicolumn{2}{|c|}{43} \\
\hline \multicolumn{7}{|l|}{ n-3 LCPUFA } \\
\hline Tertile $1^{c}$ & 1.00 & 1.00 & 1.00 & 1.00 & 1.00 & 1.00 \\
\hline Tertile $2^{d}$ & $1.12(0.63,2.02)$ & $0.93(0.49,1.77)$ & 1.16 (0.69 to 1.95$)$ & $1.20(0.70,2.06)$ & $0.43(0.21,0.88)$ & $0.48(0.22,1.06)$ \\
\hline Tertile $3^{\mathrm{e}}$ & $1.45(0.84,2.53)$ & $1.55(0.87,2.76)$ & $1.16(0.69,1.95)$ & $1.33(0.77,2.28)$ & $0.38(0.18,0.80)$ & $0.38(0.17,0.83)$ \\
\hline$P$ for trend & 0.17 & 0.11 & 0.59 & 0.30 & 0.007 & 0.01 \\
\hline \multicolumn{7}{|l|}{ Total fish } \\
\hline Tertile $1^{f}$ & 1.00 & 1.00 & 1.00 & 1.00 & 1.00 & 1.00 \\
\hline Tertile $2^{g}$ & $1.68(0.97,2.89)$ & $1.51(0.84,2.72)$ & $0.85(0.50,1.44)$ & $0.88(0.51,1.52)$ & $0.87(0.44,1.71)$ & $0.94(0.45,1.98)$ \\
\hline Tertile $3^{h}$ & $1.02(0.55,1.88)$ & $1.19(0.63,2.27)$ & $1.05(0.63,1.74)$ & $1.10(0.65,1.85)$ & $0.56(0.26,1.24)$ & $0.66(0.29,1.53)$ \\
\hline$P$ for trend & 0.96 & 0.60 & 0.84 & 0.70 & 0.16 & 0.34 \\
\hline
\end{tabular}

Hazard ratios and 95\% confidence intervals were calculated using Cox proportional hazards. ${ }^{a}$ Diabetes was defined as clinically diagnosed, or as having a fasting glucose $\geq 7.0$ or a non-fasting glucose $\geq 11.1 \mathrm{mmol} / \mathrm{L}$. ${ }^{\mathrm{b}}$ Multivariate model adjusted for age (continuous), sex, fasting (yes or no), current smoker (yes or no), extent of coronary artery disease (non-significant; single, double, or triple vessel), left ventricular ejection fraction (continuous), serum triglycerides (continuous), baseline acute coronary syndrome (yes or no), baseline percutaneous coronary intervention (yes or no), baseline coronary artery bypass graft surgery (yes or no), and treatment with folic acid or vitamin B6 supplements (yes or no). ${ }^{c} n=337$ in non-diabetic, $n=349$ in pre-diabetic, and $n=105$ in diabetic patients. ${ }^{d} n=338$ in non-diabetic, $n=350$ in pre-diabetic, and $n=106$ in diabetic patients. ${ }^{e} n=337$ in non-diabetic, $n=350$ in pre-diabetic, and $n=106$ in diabetic patients. ${ }^{f} n=339$ in non-diabetic, $n=354$ in pre-diabetic, and $n=105$ in diabetic patients. ${ }^{9} n=335$ in non-diabetic, $n=342$ in pre-diabetic, and $n=108$ in diabetic patients. $h_{n}=338$ in non-diabetic, $n=353$ in pre-diabetic, and $n=104$ in diabetic patients. HbA1c, glycosylated hemoglobin; $n-3$ LCPUFA, $n-3$ long-chain polyunsaturated fatty acids (eicosapentaenoic acid, docosapentaenoic acid, and docosahexaenoic acid). 
Table 4 Risk of acute myocardial infarction (separate fatal and non-fatal) by dietary n-3 LCPUFA tertiles (as a percentage of total energy intake)

\begin{tabular}{|c|c|c|c|}
\hline & $\begin{array}{c}\text { Non-diabetes } \\
\text { (HbA1c }<5.7 \%, n=1,012)\end{array}$ & $\begin{array}{c}\text { Pre-diabetes } \\
(\mathrm{HbA} 1 \mathrm{c} \geq 5.7 \%, \mathrm{n}=1,049)\end{array}$ & Diabetes $(n=317)^{a}$ \\
\hline Fatal AMI (events) & 16 & 20 & 18 \\
\hline Tertile $1^{b}$ & 1.00 & 1.00 & 1.00 \\
\hline Tertile $2^{c}$ & $1.98(0.36,10.82)$ & $1.85(0.56,6.15)$ & $0.39(0.13,1.15)$ \\
\hline Tertile $3^{d}$ & $4.79(1.05,21.90)$ & $1.84(0.56,6.13)$ & $0.22(0.06,0.81)$ \\
\hline$P$ for trend & 0.02 & 0.34 & 0.02 \\
\hline Non-fatal AMI (events) & 61 & 68 & 25 \\
\hline Tertile $1^{b}$ & 1.00 & 1.00 & 1.00 \\
\hline Tertile $2^{c}$ & 1.03 (0.55 to 1.93$)$ & 1.04 (0.58 to 1.87$)$ & 0.45 (0.17 to 1.20$)$ \\
\hline Tertile $3^{\mathrm{d}}$ & $1.10(0.60$ to 2.04$)$ & 1.04 (0.58 to 1.86$)$ & 0.52 (0.20 to 1.32$)$ \\
\hline$P$ for trend & 0.75 & 0.91 & 0.14 \\
\hline
\end{tabular}

Hazard ratios and 95\% confidence intervals were calculated using Cox proportional hazards. The model was adjusted for age (continuous) and sex. ${ }^{\circ}$ Diabetes was defined as clinically diagnosed, or as having a fasting glucose $\geq 7.0$ or a non-fasting glucose $\geq 11.1 \mathrm{mmol} / \mathrm{L}$. ${ }^{\mathrm{b}} \mathrm{n}=337 \mathrm{in}$ non-diabetic, $\mathrm{n}=349$ in pre-diabetic, and $n=105$ in diabetic patients. ${ }^{c} n=338$ in non-diabetic, $n=350$ in pre-diabetic, and $n=106$ in diabetic patients. ${ }^{d} n=337$ in non-diabetic, $n=350$ in pre-diabetic, and $n=106$ in diabetic patients. HbA1c, glycosylated hemoglobin; $n-3$ LCPUFA, n-3 long-chain polyunsaturated fatty acids (eicosapentaenoic acid,

docosapentaenoic acid, and docosahexaenoic acid).

Furthermore, patients without diabetes who experienced an AMI did also have a lower HbA1c than those who did not have an AMI event (mean \pm SD $4.77 \pm 0.63$ versus $4.92 \pm 0.60, P=0.04$ ). This association was more pronounced among those who had a fatal AMI event (mean \pm SD $4.55 \pm 0.68$ versus $4.92 \pm 0.60, P=0.02$ ). No such differences were observed in those with pre-diabetes or diabetes.

\section{Discussion}

The main finding in this observational cohort study among patients with established CAD was that a high intake of $n-3$ LCPUFAs was associated with a reduced risk of total AMI, independent of $\mathrm{HbA1c}$, in patients with diabetes, but with an increased risk of fatal AMI and with lower HbA1c in those without impaired glucose metabolism.

One of the strengths of this study was its large, wellcharacterized population with long-term follow-up and extensive dietary information. Data are scarce on the association between dietary intake of n-3 LCPUFA and AMI in statin-treated patients with $\mathrm{CAD}$, since most previous studies have based their results on circulating n-3 LCPUFAs and many investigations have been performed in groups that did not receive statins. This study helps address this gap in data. All endpoints in the current study were validated by a committee blinded to the dietary information.

This study also had certain limitations. Our study had limited power to detect significant effects due to the smaller sample size of sub-groups and the low event rate primarily in the non-diabetes group. Furthermore, FFQs were not checked for errors when received at the study center, and participants with extreme values or partially missing reported intakes were excluded ahead of this sub-study. The remaining data were considered valid, as dietary intakes were comparable to previous surveys in the region using the same questionnaire [30]. Information on dietary habits was collected at baseline, reflecting the average intake during the past year, whereas no information on dietary habits was collected during follow-up. Thus, there is a possibility of a regression dilution bias, which probably would have strengthened rather than attenuated the results. Despite careful adjustments for available important covariates, prospective cohort studies are typically limited by confounding from both unmeasured and inappropriately measured factors.

Similar to our previous investigation [20], a study among post-AMI patients did not report any overall relations between n-3 LCPUFAs and cardiovascular events [31]. However, in accordance with our current results, a post hoc analysis among participants with diabetes revealed a strong decline in ventricular arrhythmia-related events and fatal AMI with increased n-3 LCPUFA intake [32]. Other studies have also indicated that a high intake may reduce the risk of non-fatal AMI [33-36]. A recent study concluded that n-3 PUFA supplementation might have the ability to reduce cardiovascular events in patients not treated with statins [37], whereas no additional benefits were observed among statin users [37]. The majority of patients in the present study were treated with statins. Thus, our data indicate that $\mathrm{n}-3$ LCPUFA intake is associated with AMI risk, and particularly fatal events, also in statin users.

The main question is whether our findings are observed by chance or report real effects of n-3 LCPUFA intake. No effects of n-3 LCPUFA supplementation were revealed in the large ORIGIN study among dysglycemic patients [18]. These participants had a low baseline dietary intake of $n-3$ LCPUFAs, and even after receiving study treatment, daily n-3 LCPUFA intake was only about half compared to those having the highest intakes in our population. Additionally, 
olive oil was used as placebo in ORIGIN as well as in several other randomized trials [38]. This oil contains various FAs, and its use as placebo may thus have influenced the results. Furthermore, participants in ORIGIN had a median HbA1c of $6.4 \%$, whereas patients with diabetes in the current study had a median HbA1c of $7.2 \%$. Patients with HbA1c $\geq 9.0 \%$ were excluded from ORIGIN, whereas those with fasting plasma glucose $\geq 6.1 \mathrm{mmol} / \mathrm{L}$ were included. In a separate analysis in our cohort, we included all patients with $\mathrm{HbA1c} \geq 6.5 \%$ together with the patients diagnosed with diabetes, which attenuated the results. Based on these considerations, the diabetes group in our study differs clearly from the dysglycemic patients in ORIGIN, having a similar average HbA1c as in our sub-group of patients with pre-diabetes where no association with n-3 LCPUFA was observed. Notably, the ACCORD study among patients with diabetes having baseline median HbA1c 8.1\% demonstrated adverse effects with an increased mortality after aggressive glucose lowering treatment [19]. Thus, the overall intensive glucose lowering in ORIGIN may also have influenced outcome following n-3 LCPUFA supplementation.

Dietary n-3 LCPUFAs are predominantly present in fish and seafood, in which oily fish is a major source. Existing international guidelines recommend an n-3 LCPUFA intake of at least $250 \mathrm{mg} /$ day or two servings of oily fish per week [39]. Despite the observed associations between dietary n-3 LCPUFAs and AMI risk, no clear associations could be seen for fish intake. This might be explained by a frequent use of cod liver and/or fish oils among those having the highest intakes of n-3 LCPUFAs, with 70\% using such supplements in the upper tertile (data not shown). Even though n-3 LCPUFA supplements like cod liver and fish oils were frequently used, fish consumption was also relatively high in this cohort. Thus, we cannot exclude that other fish ingredients may have influenced the results.

Another prominent finding in the present study was the strong association between a high intake of n-3 LCPUFAs and fatal AMI in patients without diabetes with HbA1c $<5.7 \%$. Dietary intake of high-dose n-3 LCPUFA has also in some previous studies been associated with adverse effects. A study in South Wales on male patients with angina pectoris revealed an increased risk of cardiac death among participants advised to eat oily fish or fish oil capsules [40]. Furthermore, a canine model showed a proarrhythmic effect after high-dose n-3 PUFA supplementation in dogs not originally vulnerable to ischemia [41].

Through a post hoc comparison within the non-diabetic group, we demonstrated an overall lower HbA1c in those having the highest intake of n-3 LCPUFAs and in those who experienced a fatal AMI compared to the other individuals within the non-diabetic group. A previous prospective cohort study demonstrated an increased risk of all-cause death among individuals with HbA1c $<5.0 \%$ (no diabetes) [42]. A link has been demonstrated between hypoglycemia, endothelial dysfunction, and increased oxidative stress [43], which could produce a certain metabolic profile. Accordingly, high-dose fish oil supplementation has also been associated with increased oxidative damage in rats [44]. In view of our own observations, it is curious to note that when fasted, dienoyl-CoA reductase (Decr) null mutant mice develop hypoglycemia and accumulate PUFAs in their tissues, indicating an impaired mitochondrial $\beta$-oxidation [45]. This may further suggest a reverse relationship between PUFAs and blood glucose in fasted individuals. Our findings could imply that high-dose n-3 LCPUFA consumption among patients without diabetes or impairment of glucose tolerance might reduce overall blood glucose and increase the risk of fatal AMI. Notably, no association was seen between $\mathrm{HbAlc}$ and the $\mathrm{n}-3$ LCPUFA effects among patients with diabetes.

Altogether, additional studies are needed to validate our findings and further elucidate mechanisms behind the observed associations. Based on future research, it should be concluded whether it is time for a reassessment of the current dietary advices on n-3 LCPUFAs in secondary prevention of CAD [3].

\section{Conclusions}

In this cohort of patients with established CAD, a high intake of n-3 LCPUFAs was associated with reduced risk of AMI, independent of $\mathrm{HbA1c}$, in patients with diabetes. In patients without diabetes, a high intake was associated with increased risk of fatal AMI and lower HbA1c. These findings should motivate further studies on potential beneficial or adverse effects of a high n-3 LCPUFA intake in sub-groups of patients with CAD.

\section{Abbreviations}

\%TE: Percentage of total energy; AMl: Acute myocardial infarction; CABG: Coronary artery bypass graft surgery; CAD: Coronary artery disease; Cl: Confidence interval; DHA: Docosahexaenoic acid; DPA: Docosapentaenoic acid (n-3); EPA: Eicosapentaenoic acid; FA: Fatty acid; FFQ: Food frequency questionnaire; HbA1c: Glycosylated hemoglobin; HR: Hazard ratio; LCPUFA: Long-chain polyunsaturated fatty acid; n-3: Omega-3; PCl: Percutaneous coronary intervention; SD: Standard deviation; WENBIT: Western Norway B-Vitamin Intervention Trial; wt\%: Percentage by weight.

\section{Competing interests}

The authors declare that they have no competing interests.

\section{Authors' contributions}

RKB and ON designed research; ES, ERP, GFTS, HSH, EWR, PB, KM, and ON conducted research; ES, RS, PB, KM analyzed data or performed statistical analysis; $E S$ and $O N$ wrote the paper; ES had primary responsibility for final content; ES, BB, JKH, RKB, and ON interpreted data; ES, GFTS, HSH, EWR, BB, $\mathrm{RS}, \mathrm{PB}, \mathrm{JKH}, \mathrm{JEN}, \mathrm{DWTN}, \mathrm{RKB}$, and ON critically revised the manuscript. All listed authors take responsibility for all aspects of the reliability and freedom from bias of the data presented and their discussed interpretation. All authors read and approved the final manuscript.

\section{Acknowledgements}

We thank all WENBIT coworkers at Haukeland and Stavanger University Hospitals. Especially, we thank Dr Marta Ebbing for having collected and verified WENBIT data and endpoints. We also thank the staff at the 
Department of Nutrition, University of Oslo, for help with extracting the dietary data. We are grateful to Liv Kristine Øysæd, Kari Helland Mortensen, Randi Sandvik, and Marte Aanestad for excellent technical assistance during FA composition analyses. Funding of this project was provided by the Advanced Research Program and Research Council of Norway; the Department of Heart Disease at Haukeland University Hospital; the Norwegian Foundation for Health and Rehabilitation; the Norwegian Heart and Lung Patient Organization; the Norwegian Ministry of Health and Care Services; the Western Norway Regional Health Authority; MitoHealth; and the University of Bergen. The main sponsors were nonprofit organizations with no participating role in the trial. JEN, DWTN, RKB, and ON obtained funding.

\section{Author details}

'Department of Clinical Science, University of Bergen, 5021 Bergen, Norway. ${ }^{2}$ Department of Heart Disease, Haukeland University Hospital, Bergen, Norway. ${ }^{3}$ Bevital AS, Bergen, Norway. ${ }^{4}$ Department of Biochemistry and Biocenter Oulu, University of Oulu, Oulu, Finland. ${ }^{5}$ MitoHealth Centre for Bioactive Food Components and Prevention of Lifestyle Diseases, Bergen, Norway. ${ }^{6}$ Division of Cardiology, Stavanger University Hospital, Stavanger, Norway.

Received: 5 July 2013 Accepted: 12 September 2013

Published: 8 October 2013

\section{References}

1. Mozaffarian D, Rimm EB: Fish intake, contaminants, and human health: evaluating the risks and the benefits. JAMA 2006, 296(15):1885-1899.

2. Roth EM, Harris WS: Fish oil for primary and secondary prevention of coronary heart disease. Curr Atheroscler Rep 2010, 12(1):66-72.

3. Kris-Etherton PM, Harris WS, Appel L: Omega-3 fatty acids and cardiovascular disease: new recommendations from the American Heart Association. Arterioscler Thromb Vasc Biol 2003, 23(2):151-152.

4. Kwak SM, Myung SK, Lee YJ, Seo HG: Efficacy of omega-3 fatty acid supplements (eicosapentaenoic acid and docosahexaenoic acid) in the secondary prevention of cardiovascular disease: a meta-analysis of randomized, double-blind, placebo-controlled trials. Arch Intern Med 2012, 172(9):686-694.

5. Rizos EC, Ntzani EE, Bika E, Kostapanos MS, Elisaf MS: Association between omega-3 fatty acid supplementation and risk of major cardiovascular disease events: a systematic review and meta-analysis. JAMA 2012, 308(10):1024-1033.

6. Risk and Prevention Study Collaborative Group, Roncaglioni MC, Tombesi M, Avanzini F, Barlera S, Caimi V, Longoni P, Marzona I, Milani V, Silletta MG, Tognoni G, Marchioli R: $n-3$ fatty acids in patients with multiple cardiovascular risk factors. N Engl J Med 2013, 368(19):1800-1808.

7. Tavazzi L, Maggioni AP, Marchioli R, Barlera S, Franzosi MG, Latini R, Lucci D, Nicolosi GL, Porcu M, Tognoni G: Effect of $n-3$ polyunsaturated fatty acids in patients with chronic heart failure (the GISSI-HF trial): a randomised, double-blind, placebo-controlled trial. Lancet 2008, 372(9645):1223-1230.

8. Nodari S, Triggiani M, Campia U, Manerba A, Milesi G, Cesana BM, Gheorghiade M, Dei Cas L: Effects of $n-3$ polyunsaturated fatty acids on left ventricular function and functional capacity in patients with dilated cardiomyopathy. J Am Coll Cardiol 2011, 57(7):870-879.

9. Ghio S, Scelsi L, Latini R, Masson S, Eleuteri E, Palvarini M, Vriz O, Pasotti M, Gorini M, Marchioli R, Maggioni A, Tavazzi L, GISSI-HF investigators: Effects of $n-3$ polyunsaturated fatty acids and of rosuvastatin on left ventricular function in chronic heart failure: a substudy of GISSI-HF trial. Eur J Heart Fail 2010, 12(12):1345-1353.

10. Deaton C, Mamas MA, Rutter MK, Gibson M, Bowell S, Byrne R, Coezy K, Gow J, Williams S: Glucose and insulin abnormalities in patients with heart failure. Eur I Cardiovasc Nurs 2011, 10(2):75-87.

11. Fallow GD, Singh J: The prevalence, type and severity of cardiovascular disease in diabetic and non-diabetic patients: a matched-paired retrospective analysis using coronary angiography as the diagnostic tool. Mol Cell Biochem 2004, 261(1-2):263-269.

12. Hu FB, van Dam RM, Liu S: Diet and risk of Type II diabetes: the role of types of fat and carbohydrate. Diabetologia 2001, 44(7):805-817.

13. Nkondjock A, Receveur O: Fish-seafood consumption, obesity, and risk of type 2 diabetes: an ecological study. Diabetes Metab 2003, 29(6):635-642.
14. Salmeron J, Hu FB, Manson JE, Stampfer MJ, Colditz GA, Rimm EB, Willett WC: Dietary fat intake and risk of type 2 diabetes in women. Am J Clin Nutr 2001, 73(6):1019-1026

15. Meyer KA, Kushi LH, Jacobs DR Jr, Folsom AR: Dietary fat and incidence of type 2 diabetes in older lowa women. Diabetes Care 2001, 24(9):1528-1535.

16. Wang L, Folsom AR, Zheng ZJ, Pankow JS, Eckfeldt JH: Plasma fatty acid composition and incidence of diabetes in middle-aged adults: the Atherosclerosis Risk in Communities (ARIC) Study. Am J Clin Nutr 2003, 78(1):91-98.

17. van Dam RM, Willett WC, Rimm EB, Stampfer MJ, Hu FB: Dietary fat and meat intake in relation to risk of type 2 diabetes in men. Diabetes Care 2002, 25(3):417-424.

18. ORIGIN Trial Investigators, Bosch J, Gerstein HC, Dagenais GR, Diaz R, Dyal L, Jung $H$, Maggiono AP, Probstfield J, Ramachandran A, Riddle MC, Rydén LE, Yusuf S: $\mathrm{n}-3$ fatty acids and cardiovascular outcomes in patients with dysglycemia. N Engl I Med 2012, 367(4):309-318.

19. Action to Control Cardiovascular Risk in Diabetes Study Group, Gerstein HC, Miller ME, Byington RP, Goff DC Jr, Bigger JT, Buse JB, Cushman WC, Genuth S, Ismail-Beigi F, Grimm RH Jr, Probstfield JL, Simons-Morton DG, Friedewald WT: Effects of intensive glucose lowering in type 2 diabetes. N Engl J Med 2008, 358(24):2545-2559.

20. Manger MS, Strand E, Ebbing M, Seifert R, Refsum H, Nordrehaug JE, Nilsen DW, Drevon CA, Tell GS, Bleie O, Vollset SE, Pedersen ER, Nygård O: Dietary intake of $\mathrm{n}-3$ long-chain polyunsaturated fatty acids and coronary events in Norwegian patients with coronary artery disease. Am J Clin Nutr 2010, 92(1):244-251.

21. Ebbing M, Bleie O, Ueland PM, Nordrehaug JE, Nilsen DW, Vollset SE, Refsum H, Pedersen EK, Nygard O: Mortality and cardiovascular events in patients treated with homocysteine-lowering $B$ vitamins after coronary angiography: a randomized controlled trial. JAMA 2008, 300(7):795-804.

22. Andersen LF, Solvoll K, Drevon CA: Very-long-chain $n-3$ fatty acids as biomarkers for intake of fish and n-3 fatty acid concentrates. Am J Clin Nutr 1996, 64(3):305-311.

23. Andersen LF, Solvoll K, Johansson LR, Salminen I, Aro A, Drevon CA: Evaluation of a food frequency questionnaire with weighed records, fatty acids, and alpha-tocopherol in adipose tissue and serum. Am J Epidemiol 1999, 150(1):75-87.

24. Biroccio A, Urbani A, Massoud R, di llio C, Sacchetta P, Bernardini S, Cortese C, Federici G: A quantitative method for the analysis of glycated and glutathionylated hemoglobin by matrix-assisted laser desorption ionization-time of flight mass spectrometry. Anal Biochem 2005, 336(2):279-288.

25. Strand E, Bjorndal B, Nygard O, Burri L, Berge C, Bohov P, Christensen BJ, Berge $K$, Wergedahl $H$, Viste A, Berge RK: Long-term treatment with the pan-PPAR agonist tetradecylthioacetic acid or fish oil is associated with increased cardiac content of $\mathrm{n}-3$ fatty acids in rat. Lipids Health Dis 2012, 11(1):82.

26. Levey AS, Stevens LA, Schmid CH, Zhang YL, Castro AF 3rd, Feldman HI, Kusek JW, Eggers P, Van Lente F, Greene T, Coresh J, CKD-EPI (Chronic Kidney Disease Epidemiology Collaboration): A new equation to estimate glomerular filtration rate. Ann Intern Med 2009, 150(9):604-612.

27. Alpert JS, Thygesen K, Antman E, Bassand JP: Myocardial infarction redefined-a consensus document of The Joint European Society of Cardiology/American College of Cardiology Committee for the redefinition of myocardial infarction. J Am Coll Cardiol 2000, 36(3):959-969.

28. Inzucchi SE: Clinical practice. Diagnosis of diabetes. N Eng/ J Med 2012, 367(6):542-550.

29. Verification SSoB: Biochemical verification of tobacco use and cessation. Nicotine Tob Res 2002, 4(2):149-159.

30. Berstad P, Konstantinova SV, Refsum H, Nurk E, Vollset SE, Tell GS, Ueland PM, Drevon CA, Ursin G: Dietary fat and plasma total homocysteine concentrations in 2 adult age groups: the Hordaland Homocysteine Study. Am J Clin Nutr 2007, 85(6):1598-1605

31. Kromhout D, Giltay EJ, Geleijnse JM: $n-3$ fatty acids and cardiovascular events after myocardial infarction. N Engl I Med 2010, 363(21):2015-2026.

32. Kromhout D, Geleijnse JM, de Goede J, Oude Griep LM, Mulder BJ, de Boer MJ, Deckers JW, Boersma E, Zock PL, Giltay El: n-3 fatty acids, ventricular arrhythmia-related events, and fatal myocardial infarction in postmyocardial infarction patients with diabetes. Diabetes Care 2011, 34(12):2515-2520.

33. He K, Song Y, Daviglus ML, Liu K, Van Horn L, Dyer AR, Greenland P: Accumulated evidence on fish consumption and coronary heart disease mortality: a meta-analysis of cohort studies. Circulation 2004 109(22):2705-2711. 
34. Iso H, Kobayashi M, Ishihara J, Sasaki S, Okada K, Kita Y, Kokubo Y, Tsugane S: Intake of fish and n3 fatty acids and risk of coronary heart disease among Japanese: the Japan Public Health Center-Based (JPHC) Study Cohort I. Circulation 2006, 113(2):195-202.

35. de Goede J, Geleijnse JM, Boer JM, Kromhout D, Verschuren WM: Marine (n-3) fatty acids, fish consumption, and the 10-year risk of fatal and nonfatal coronary heart disease in a large population of Dutch adults with low fish intake. J Nutr 2010, 140(5):1023-1028.

36. Hu FB, Bronner L, Willett WC, Stampfer MJ, Rexrode KM, Albert CM, Hunter D, Manson JE: Fish and omega-3 fatty acid intake and risk of coronary heart disease in women. JAMA 2002, 287(14):1815-1821.

37. Eussen SR, Geleijnse JM, Giltay EJ, Rompelberg CJ, Klungel OH, Kromhout D: Effects of n-3 fatty acids on major cardiovascular events in statin users and non-users with a history of myocardial infarction. Eur Heart J 2012, 33(13):1582-1588.

38. Golomb BA, Erickson LC, Koperski S, Sack D, Enkin M, Howick J: What's in placebos: who knows? Analysis of randomized, controlled trials. Ann Intern Med 2010, 153(8):532-535.

39. Bresson JL, Flynn A, Heinonen M, Hulshof K, Korhonen H, Lagiou P, Løvik M, Marchelli R, Martin A, Moseley B, Przyrembel H, Salminen S, Strain S(JJ), Strobel S, Tetens I, van den Berg H, van Loveren H, Verhagen H: Scientific Opinion of the Panel on Dietetic products, Nutrition and Allergies on a request from European Commission related to labelling reference intake values for n-3 and n-6 polyunsaturated fatty acids. EFSA Journal 2009, 1176:1-11.

40. Burr ML, Ashfield-Watt PA, Dunstan FD, Fehily AM, Breay P, Ashton T, Zotos PC, Haboubi NA, Elwood PC: Lack of benefit of dietary advice to men with angina: results of a controlled trial. Eur J Clin Nutr 2003, 57(2):193-200.

41. Billman GE, Carnes CA, Adamson PB, Vanoli E, Schwartz PJ: Dietary omega-3 fatty acids and susceptibility to ventricular fibrillation: lack of protection and a proarrhythmic effect. Circ Arrhythm Electrophysiol 2012, 5(3):553-560.

42. Aggarwal V, Schneider AL, Selvin E: Low hemoglobin A(1c) in nondiabetic adults: an elevated risk state? Diabetes Care 2012, 35(10):2055-2060.

43. Wang J, Alexanian A, Ying R, Kizhakekuttu TJ, Dharmashankar K, Vasquez-Vivar J, Gutterman DD, Widlansky ME: Acute exposure to low glucose rapidly induces endothelial dysfunction and mitochondrial oxidative stress: role for AMP kinase. Arterioscler Thromb Vasc Biol 2012, 32(3):712-720.

44. Vigerust NF, Cacabelos D, Burri L, Berge K, Wergedahl H, Christensen B, Portero-Otin M, Viste A, Pamplona R, Berge RK, Bjørndal B: Fish oil and 3-thia fatty acid have additive effects on lipid metabolism but antagonistic effects on oxidative damage when fed to rats for 50 weeks. J Nutr Biochem 2012, 23(11):1384-1393.

45. Miinalainen IJ, Schmitz W, Huotari A, Autio KJ, Soininen R, Ver Loren van Themaat E, Baes M, Herzig KH, Conzelmann E, Hiltunen JK: Mitochondrial 2,4-dienoyl-CoA reductase deficiency in mice results in severe hypoglycemia with stress intolerance and unimpaired ketogenesis. PLoS Genet 2009, 5(7):e1000543.

doi:10.1186/1741-7015-11-216

Cite this article as: Strand et al:: Dietary intake of $n-3$ long-chain polyunsaturated fatty acids and risk of myocardial infarction in coronary artery disease patients with or without diabetes mellitus: a prospective cohort study. BMC Medicine 2013 11:216.

\section{Submit your next manuscript to BioMed Central and take full advantage of:}

- Convenient online submission

- Thorough peer review

- No space constraints or color figure charges

- Immediate publication on acceptance

- Inclusion in PubMed, CAS, Scopus and Google Scholar

- Research which is freely available for redistribution

Submit your manuscript at www.biomedcentral.com/submit 